Cadernos de Arquitetura e Urbanismo, v.17, n.21, 20 sem. 2010 
1. Este artigo resulta de trabalhos realizados pelo Núcleo Jurídico de Políticas Públicas/Opur (Nujup) do Programa de Pós-graduação em Direito da PUC Minas, em parceria com o Observatório de Políticas Urbanas da Proex/PUC Minas, ambos integrantes da Rede Nacional Observatório das Metrópoles.

2. Mestre em Ciências Sociais pela PUC Minas, pesquisadora e extensionista do Observatório de Políticas Urbanas da Proex/PUC Minas, que integra a Rede Nacional Observatório das Metrópoles/ Ippur, pesquisadora do Nujup.

3. Assistente social, pesquisadora e extensionista do Observatório de Políticas Urbanas da Proex/PUC Minas, que integra a Rede Nacional Observatório das Metrópoles/lppur, pesquisadora do Nujup.

4. Doutora em Direito, professora do Programa de Pós-graduação em Direito e da Faculdade Mineira de Direito da PUC Minas, coordenadora do Núcleo Jurídico de Políticas Públicas (Nujup), pesquisadora da Rede Nacional Observatório das Metrópoles/lppur. 


\title{
DIREITO À MORADIA: OS PLANOS DIRETORES DA RMBH APLICAM O ESTATUTO DA CIDADE E A CONSTITUIÇÃO FEDERAL DE 1988?'
}

RIGHTTO THE HOUSING: THE MASTERS PLANS OFTHE RMBH THEY APPLY OF CITY'S STATUTE AND THE FEDERAL CONSTITUTION OF 1988?

Naiane Loureiro dos Santos ${ }^{2}$

Circlaine da Cruz Santos Faria ${ }^{3}$

Marinella Machado Araújo ${ }^{4}$

\section{Resumo}

Este artigo objetiva discutir se os planos diretores da Região Metropolitana de Belo Horizonte (RMBH) aplicam os instrumentos de política urbana regulados pela Constituição Federal de 1988 e pelo Estatuto da Cidade, Lei n. 10.257, de 10 de julho de 2001. E, em caso afirmativo, se essa previsão pode ser considerada legítima segundo os fundamentos da democracia contestatória de Philip Pettit, a soberania popular como procedimento de Jürgen Habermas e o modelo de Estado Democrático de Direito brasileiro. Objetiva ainda divulgar os resultados da pesquisa intitulada "Direito à moradia: mapeamento das políticas públicas e das experiências alternativas de habitação popular da Região Metropolitana de Belo Horizonte (RMBH)", financiada em 2007 pelo Fundo de Incentivo à Pesquisa da PUC Minas. A partir dos instrumentos de política urbana que concretizam o direito à moradia, essa pesquisa apresenta análise crítica da gestão da política habitacional nos 34 municípios que integram a RMBH. Os resultados apontam os avanços detectados e as tendências das políticas públicas habitacionais nesses municípios. Considerado direito fundamental social somente a partir da publicação da Emenda Constitucional n. 26, de 2000, a concretização do direito à moradia ainda permanece um desafio para o poder público municipal. Nesse contexto, a análise enfatiza o processo democrático participativo de formulação das políticas habitacionais locais.

Palavras-chave: Direito à moradia; Plano Diretor Participativo; Democracia participativa; Região Metropolitana de Belo Horizonte $(\mathrm{RMBH})$.

\begin{abstract}
This article aims (i) to argue if the masters plans of the Region Metropolitan of Belo Horizonte (RMBH) municipalities apply the instruments of urban politics, regulated for the Federal Constitution of 1988 and the City Statute, Law n. 10.257, 10th July, 2001. Then, in affirmative case, (i.a) if those plans can be considered legitimate according to the participatory democracy theory of Philip Pettit or the popular sovereignty procedure of Jürgen Habermas in regarding to the model of Democratic Brazilian Rule of Law. (ii) It also aims to divulge the results of the research intitled "Right
\end{abstract}


5. Esse entendimento é resultado da interpretação dos artigos 24 e 30 do texto constitucional e já reconhecido pelo Supremo Tribunal Federal.

6.Por esse princípio, unidades políticas de uma federação devem atuar de forma subsidiária dentro de suas competências constitucionais. Assim, as unidades federativas mais próximas do interesse público têm prioridade na solução

dos conflitos de interesse, sendo que apenas na ausência das condições necessárias para a sua resolução atuariam as unidades de competência mais abrangente (União e Estadosmembros)

Cadernos de Arquitetura e Uthanismo, v.17, n.21, 2 sem. 2010 to the housing: Mapping of the public politics and the alternative experiences of popular habitation of the Region Metropolitan of Belo Horizonte (RMBH)", financed in 2007 by PUC Minas Research Found - FIP. Considering the instruments of urban politics that materialize right to the housing, this research presents critical analysis of the management of the habitacional politics in the 34 cities that integrate the $\mathrm{RMBH}$. The results point the detected advances and the trends of the housing public policies in these cities. Considered social basic right only from the publication of Constitutional Emendation n. 26, of 2000, the concretion of the right to housing still remains a challenge itself, which Public Power Municipal should be able to deal with. In this context, the analysis emphasizes the participative democratic process of formularization of the local housing policies.

Key words: Right to housing; Participatory Master Plan; Participatory democracy; Metropolitan Region of Belo Horizonte (RMBH).

\section{A relação entre política de desenvolvimento urbano, instrumentos de políticas urbanas e plano diretor}

As políticas públicas são ações que o Estado promove no exercício de sua função executiva para alcançar os interesses públicos que concretizam os direitos garantidos pela ordem constitucional. No Brasil, a Constituição de 1988, ao regular a política de desenvolvimento urbano, determinou tratar-se de competência concorrente entre União, Estados-membros, Distrito Federal e municípios. ${ }^{5}$ Contudo, adotou o princípio federativo da subsidiariedade $^{6}$ ao atribuir aos municípios função normativa principal. Assim, de acordo com o artigo 182 da Constituição de 1988, cabe aos municípios a elaboração de planos diretores, leis municipais que funcionam como instrumentos básicos da política de desenvolvimento urbano $\left(\S 1^{\circ}\right)$, pois estabelecem as diretrizes gerais (i) de ordenação do pleno desenvolvimento das funções sociais da cidade e da propriedade e (ii) da garantia do bem-estar dos habitantes da cidade (caput).

Apesar de assumirem diversos objetivos, diferentes características e formatos institucionais, as políticas públicas apresentam características gerais. Azevedo (2003) identifica duas características gerais das políticas públicas: (i) a busca do consenso em torno do que se pretende fazer e deixar de fazer e (ii) a definição de normas e o processamento de conflitos. Assim, (i) quanto maior o consenso, melhores condições de aprovação e implementação das políticas propostas. Por outro lado, (ii) as políticas públicas tanto podem estabelecer normas de ação, definidoras de diretrizes e instrumentos para a atuação do Estado, como os instrumentos de política urbana, previstos no Estatuto da Cidade, quanto normas-sanção para a resolução dos eventuais conflitos entre os diversos indivíduos e agentes sociais, como a tipificação de condutas criminais e a incidência de multas administrativas.

Em democracias participativas, como a instituída pela Constituição de 1988, espera-se que os processos políticos de tomada de decisões governamentais e participativas possam ser objeto de 
7. Pettit indica três formas de contestação ou de controle discursivo: o procedimental, o consultivo e o recursal.

8.Pettit considera interesse comum todo interesse que possa ser sustentado publicamente. controle social. O modelo representativo que caracteriza o Estado liberal tem se mostrado insuficiente para garantir pluralidade de direitos e respeito a diferenças, como sustenta Habermas em a Inclusão do outro (2004). A existência de leis cujo descumprimento sujeita seus infratores a alguma espécie de punição por órgãos institucionalizados pelo Estado, como proposto por Kelsen em Teoria geral do Direito e do Estado (1998), tende a tornar-se mais efetiva e eficiente se a elaboração e a execução das leis que regulam direitos e deveres é realizada de forma participativa. Habermas (2004) demonstra que a participação popular reforça a legitimidade do processo legislativo e, assim, torna mais efetiva a sua aplicação. Esse é o princípio democrático (participativo) que fundamenta a obrigatoriedade do planejamento e gestão urbanos participativos, que prevê o Estatuto da Cidade (arts. 39, §4º, e 43 a 45).

Pettit (2007) sustenta que um Estado de direito, democrático e republicano, fundado na liberdade, deve conter em seu ordenamento jurídico instrumentos de controle discursivo ${ }^{7}$ das funções públicas, ou seja, meios colocados à disposição do cidadão para que possa questionar as decisões tomadas no âmbito de atuação dos três Poderes do Estado que visam a efetivar o interesse comum. ${ }^{8}$ Não basta que possamos eleger nossos representantes (dimensão autoral da democracia). É preciso que possamos controlá-los. Esse modelo democrático Pettit (2007) denomina democracia contestatória. Dois fatores devem ser considerados para que as pessoas desfrutem da liberdade como controle discursivo: (i) capacidade raciocinativa para participar, e (ii) capacidade relacional.

\section{Políticas públicas participativas e a proposta de planejamento urbano do Estatuto da Cidade}

Nos últimos anos, sobretudo a partir da década de 1990, o debate sobre a questão democrática no Brasil voltou-se, em grande parte, para a aplicação dos instrumentos democráticos instituídos pela Constituição de 1988. Parte dessa discussão estabeleceu-se em torno dos mecanismos institucionais de participação popular na definição e no controle de políticas públicas por meio de canais de participação do tipo: conselhos municipais, orçamento participativo, elaboração do plano diretor participativo, consórcios públicos. Contudo, a cultura política brasileira e a falta de maturidade democrática do povo brasileiro têm representado obstáculos à efetividade do planejamento e gestão participativos regulados pelo Estatuto da Cidade. Legitimidade da ação participativa envolve mais do que a existência de canais institucionalizados de participação. Envolve também o enfretamento de questões como: (i) assimetria de conhecimento entre atores sociais, (ii) paridade entre a cultura política vigente no poder público e a vigente na sociedade civil, (iii) educação, capacitação e sensibilização de atores sociais.

Nesse sentido, muitos são os desafios decorrentes das práticas que envolvem a formulação e a execução de políticas públicas participativas. Talvez o maior deles seja justamente como garantir a apropriação legítima do poder político de participação tanto 
9. O Opur, em parceria com o

Nujup e outras organizações não governamentais, promove anualmente o Programa Interdisciplinar de Políticas

Públicas e Gestão Local: curso

de capacitação para conselheiros municipais e agentes sociais, com o intuito de instrumentalizar os atores sociais, fornecendo um conjunto de conceitos, teorias, métodos e técnicas que reforçam a qualificação em esferas públicas de participação popular. A partir dessa experiência, que já possui cinco edições no âmbito da Região Metropolitana de Belo Horizonte, foram identificados obstáculos à participação a partir do relato da atuação desses atores nos processos de tomadas de decisão de conselhos municipais, movimentos sociais, fóruns, ONGs associações comunitárias dos quais participam. Muitos desses relatos

demonstram que a realidade da gestão participativa não é uniforme:

ora acontece de forma consultiva, ora deliberativa, independentemente da natureza da deliberação. Esses atores sociais chegam para o curso com muitas

dúvidas, vontade política e também com muitas experiências de lutas.

Exemplos não faltam para mostrar como os processos de decisão, em suas instituições de atuação como atores sociais, são difíceis e conflituosos, sobretudo entre poder público e sociedade civil.

O mesmo foi observado na pesquisa Perfil dos Conselhos e Conselheiros

Municipais da RMBH, em 2002, atualizada parcialmente em 2005, pelo Opur - Proex/PUC Minas em parceria com a Rede Nacional Observatório das Metrópoles. De acordo com os dados coletados, vários conselhos mencionaram em suas experiências a seleção dos conteúdos que deveriam ser decididos ou votados por todos os membros do conselho e os que deveriam ser apenas consultados à sociedade civil. Para a maioria dos entrevistados não existe um equilíbrio de forças no interior dos conselhos

10. O Ministério das Cidades foi criado em 2003 com o objetivo de atuar na universalização do acesso aos direitos fundamentais vinculados à política de desenvolvimento urbano por meio do fomento a ações democráticas descentralizadas e participativas de ordenação do espaço urbano. Nesse sentido, busca-se refletir a respeito dos limites que perpassam a discussão sobre políticas públicas participativas detendo-se, principalmente, na legitimidade da participação popular.

Cadernos de Arquitetura e Urbanismo, v.17, n.21, $2^{0}$ sem. 2010 pela sociedade civil, como pelo poder público. O enfrentamento dessa questão implica, por um lado, (i) a autocrítica da forma como o poder público e sociedade civil concebem o interesse público e, por outro, (ii) o fortalecimento dos canais de participação por parte da sociedade. A experiência tem demonstrado que os canais de participação popular, que envolvem planejamento e gestão de políticas públicas, são na prática ainda pouco deliberativos no que se refere à participação da sociedade. ${ }^{9} \mathrm{O}$ processo de implantação da democracia participativa é lento. E o exercício da democracia é um processo contínuo e dialógico, como sustenta Habermas (2004).

Se, por um lado, a democracia brasileira avançou na medida em que produziu leis, como o Estatuto da Cidade, que reconhecem o direito à participação e institucionalizam canais de interlocução entre sociedade civil e poder público com o objetivo de viabilizar o exercício cooperado das funções do Estado, por outro, a legitimidade da atuação desses canais de participação, que é diretamente proporcional à sua apropriação pela sociedade civil, ainda representa um desafio.

\section{A garantia do direito à moradia com principal função social da cidade}

Desde a teoria funcionalista de Le Corbusier consagrada pela Carta de Atenas de 1933, a habitação figura entre as funções-chave da cidade. Em que pesem as teorias sobre planejamento urbano adotarem variável social, no sentido de reconhecer a importância do habitante da cidade para a eficiência do planejamento urbano, a habitação ainda é uma das funções-chave da cidade. Tanto assim que, ao regular a política de desenvolvimento urbano, a Constituição de 1988 estabelece que a propriedade urbana cumpre sua função social quando atende às diretrizes fundamentais de ordenação da cidade expressas no plano diretor (art. 182, § $\left.2^{\circ}\right)$. Igualmente, toda a concepção das diretrizes gerais e dos instrumentos da política de desenvolvimento urbano regulada pelo Estatuto da Cidade teve por referência o direito de acesso à terra urbanizada. Isso é observado tanto pela natureza das diretrizes previstas no artigo $2^{\circ}$, como pelos fins atribuídos aos instrumentos de política urbana.

O direito à moradia somente foi alçado à condição de direito fundamental social pela Emenda Constitucional n. 26, de 2000. E, desde então, sua garantia paulatinamente vem sendo incorporada à jurisprudência da Corte Constitucional brasileira. Nesse sentido é a proferida na ADIn 2990/04 em que o STF reconheceu a constitucionalidade da lei do Distrito Federal que previa possibilidade de alienação de imóveis localizados em área de proteção ambiental, após a realização de programa de regularização fundiária sem licitação de imóveis.

\section{Planos diretores participativos da RMBH}

Ao final do ano de 2006, o Ministério das Cidades, ${ }^{10} \mathrm{em}$ parceria com o Confea (Conselho Federal de Engenharia, Arquitetura e Agronomia), como desdobramento da Campanha Nacional Cida- 
11. A campanha "Cidade para Todos" teve por objetivo sensibilizar e capacitar os atores sociais do poder público e da sociedade civil para a elaboração dos planos diretores participativos e foi realizada em 2005/2006.O mesmo foi observado na pesquisa Perfil dos Conselhos e Conselheiros Municipais da RMBH, em 2002, atualizada parcialmente em 2005, pelo Opur - Proex/PUC Minas em parceria com a Rede Nacional Observatório das Metrópoles. De acordo com os dados coletados, vários conselhos mencionaram em suas experiências a seleção dos conteúdos que deveriam ser decididos ou votados por todos os membros do conselho e os que deveriam ser apenas consultados à sociedade civil. Para a maioria dos entrevistados não existe um equilíbrio de forças no interior dos conselhos.

12. As informações obtidas são percepções dos entrevistados e não houve análise documental. Assim, podese observar algumas divergências entre as respostas dos entrevistados e dos 34 municípios pesquisados, sendo que três não constam nos bancos de dados, dois porque não enviaram suas respostas e um porque foi invalidado. de para Todos, ${ }^{11}$ realizou pesquisa como o objetivo de identificar, naquele momento, qual era o estágio do processo de elaboração dos planos diretores participativos nos municípios que se encontravam dentro dos critérios de obrigatoriedade estabelecidos pelo Estatuto da Cidade: cidades com mais de 20 mil habitantes e inseridas em regiões metropolitanas, nos termos da Resolução n. 25, de 18 de março de 2005, do Concidades (Conselho das Cidades). A pesquisa foi realizada em âmbito nacional e contou com a participação dos Creas (Conselho Regional de Engenharia, Arquitetura e Agronomia) para a sua operacionalização. No caso da Região Metropolitana de Belo Horizonte, em Minas Gerais, a pesquisa foi realizada por meio da parceria entre o Observatório de Políticas Urbanas/Proex-PUC Minas e o Crea-MG.

Os instrumentos de coleta de dados utilizados na pesquisa basearam-se em três tipos de questionários para serem aplicados: (a) ao coordenador político do plano diretor participativo no município; (b) ao coordenador técnico e (c) ao representante da sociedade civil, gerando, assim, três tipos de banco de dados, ${ }^{12}$ com os quais se trabalhou na pesquisa "Direito à moradia: mapeamento das políticas públicas e das experiências alternativas de habitação popular da Região Metropolitana de Belo Horizonte (RMBH)", financiada em 2007 pelo Fundo de Incentivo à Pesquisa da PUC Minas.

A pesquisa mostrou que num universo de 31 municípios válidos, em 26 houve respostas do coordenador político (83,87\%), em 18 do coordenador técnico $(58,06 \%)$ e em 19 houve respostas do representante da sociedade civil $(61,29 \%)$. Com base nesses resultados, considerou-se que o coordenador político teve uma maior participação no processo de elaboração dos planos diretores participativos, seguido da sociedade civil e do coordenador técnico.

No que se refere aos instrumentos urbanísticos adotados pelos municípios em seus planos diretores, estiveram mais presentes: a zona de especial interesse social (Zeis), a transferência do direito de construir, a outorga onerosa do direito de construir, o IPTU progressivo no tempo, operação urbana consorciada, parcelamento, edificação ou utilização compulsórios e contribuição de melhoria. Chamou atenção o fato de que, apesar de alguns municípios terem informado a previsão de Zeis em seus planos diretores, nenhum dos atores pesquisados considerou a existência da regularização fundiária como instrumento de política urbana.

De um modo geral, a pesquisa mostrou que em mais de $50 \%$ dos municípios da RMBH houve participação da sociedade civil no processo de elaboração dos planos diretores participativos. Entre os instrumentos de gestão democrática, previstos pelo Estatuto da Cidade no artigo 45, os mais utilizados foram os conselhos gestores, as comissões e as audiências públicas, e os menos utilizados foram os fóruns, as oficinas e palestras.

Entretanto, ao se analisar as respostas sobre a utilização ou não dos instrumentos urbanísticos regulados pelo Estatuto da Cidade nos planos diretores, observou-se divergência entre o informado pelo coordenador político, o informado pelo representante técnico e o informado pelo representante da sociedade civil. Essa 
13. Realizou-se em 2002 pesquisa financiada pelo Finep, denominada "Rede de avaliação e disseminação de experiências alternativas em habitação popular", sob coordenação nacional do Observatório das Metrópoles, sediado no Ippur/UFRJ. Para a realização dessa campanha foram criados núcleos mobilizadores estaduais, que congregavam várias instituições do poder público e sociedade civil. O Opur/ Proex e o Crea-MG faziam parte do núcleo mobilizador de Minas Gerais. divergência levou à formulação da seguinte hipótese: a participação popular informada não teria sido efetiva em razão da ausência de informação e de transparência na elaboração dos planos diretores desses municípios.

\section{Direito à moradia: mapeamento das políticas públicas e das experiências alternativas de habitação popular da Região Metropolitana de Belo Horizonte (RMBH)}

Essa pesquisa teve por objetivo traçar o panorama geral da situação da política habitacional de interesse social nos municípios da Região Metropolitana de Belo Horizonte, no que diz respeito à execução dessa política e à efetivação da participação popular nos processos participativos de tomada de decisão dos municípios. Pretendeu também fazer uma análise comparativa mediante dados de uma pesquisa ${ }^{13}$ realizada em 2002 sobre a mesma temática.

Nesses quatro anos foram identificados alguns avanços. O número de instrumentos urbanísticos aumentou em todos os municípios, segundo a informação fornecida pelos responsáveis da área. A tabela abaixo ilustra essa percepção.

Nota-se que, de modo geral, a evolução quanto ao alcance dos instrumentos urbanísticos na $\mathrm{RMBH}$ foi positiva. A maioria dos instrumentos aqui listados se difundiu consideravelmente dentro da região metropolitana no período pesquisado. Poucos instrumentos apresentaram queda quanto a seu uso nos anos de 2002 e de 2006. São eles: consórcio imobiliário, usucapião urbano e desapropriação, o que denota pouco reconhecimento pelos municípios da natureza urbanística desses instrumentos.

Por exemplo, no ano de 2006 nenhum coordenador técnico ou político alegou a existência dos instrumentos urbanísticos citados anteriormente. Contudo, entre os representantes da sociedade civil que responderam sobre a mesma questão, 10,53\% alegaram a existência do consórcio imobiliário, usucapião urbano e desapropriação, evidenciando divergência quanto à apreensão do significado desses termos.

O instrumento Estudo Prévio de Impacto Ambiental (EIA) decresceu sua participação no universo dos municípios consultados. Passou de cinco municípios, em 2002, para quatro municípios, em 2006. Do ponto de vista ambiental, isso pode significar certa depreciação quanto à qualidade da proteção do meio ambiente. Observe-se que também aqui há divergência. Dos 18 questionários respondidos pelo coordenador técnico, 22,22\% informaram haver previsão do EIA nos planos diretores de seus municípios. Já dos 19 questionários respondidos pela sociedade civil, 15,79\% consideraram haver previsão do EIA em seus planos diretores. Enquanto dos 26 questionários respondidos pelo coordenador político apenas 3,85\% consideraram existir tal previsão, ratificando a divergência.

Os demais instrumentos apresentaram considerável crescimento quanto à sua adoção por parte dos municípios da $\mathrm{RMBH}$. Destacam-se: IPTU progressivo no tempo, direito de superfície, 
Tabela 1

Instrumentos urbanísticos

\begin{tabular}{|c|c|c|c|c|c|c|c|c|c|c|c|}
\hline \multirow{3}{*}{ Instrumentos urbanísticos } & \multirow{3}{*}{\multicolumn{2}{|c|}{2002}} & \multicolumn{9}{|c|}{ Atores do plano diretor (2006) } \\
\hline & & & \multicolumn{3}{|c|}{ Sociedade civil } & \multicolumn{3}{|c|}{ Coordenador técnico } & \multicolumn{3}{|c|}{ Coordenador político } \\
\hline & & & Total & Sim & $(\%)$ & Total & Sim & $(\%)$ & Total & Sim & $(\%)$ \\
\hline Consórcio imobiliário & 0 & $0,00 \%$ & 19 & 2 & $10,53 \%$ & 18 & 0 & $0,00 \%$ & 26 & 0 & $0,00 \%$ \\
\hline Usucapião urbano & 1 & $3,23 \%$ & 19 & 2 & $10,53 \%$ & 18 & 0 & $0,00 \%$ & 26 & 0 & $0,00 \%$ \\
\hline Desapropriação & 5 & $16,13 \%$ & 19 & 2 & $10,53 \%$ & 18 & 0 & $0,00 \%$ & 26 & 0 & $0,00 \%$ \\
\hline $\begin{array}{l}\text { Concessão especial de uso para } \\
\text { fins de moradia }\end{array}$ & 2 & $6,45 \%$ & 19 & 2 & $10,53 \%$ & 18 & 1 & $5,56 \%$ & 26 & 1 & $3,85 \%$ \\
\hline Concessão de direito real de uso & 2 & $6,45 \%$ & 19 & 5 & $26,32 \%$ & 18 & 2 & $11,11 \%$ & 26 & 6 & $23,08 \%$ \\
\hline $\begin{array}{l}\text { Estudo prévio de impacto am- } \\
\text { biental (EIA) }\end{array}$ & 5 & $16,13 \%$ & 19 & 3 & $15,79 \%$ & 18 & 4 & $22,22 \%$ & 26 & 1 & $3,85 \%$ \\
\hline Contribuição de melhoria & 4 & $12,90 \%$ & 19 & 10 & $52,63 \%$ & 18 & 10 & $55,56 \%$ & 26 & 22 & $84,62 \%$ \\
\hline Direito de superfície & 1 & $3,23 \%$ & 19 & 15 & $78,95 \%$ & 18 & 11 & $61,11 \%$ & 26 & 20 & $76,92 \%$ \\
\hline IPTU progressivo no tempo & 0 & $0,00 \%$ & 19 & 14 & $73,68 \%$ & 18 & 13 & $72,22 \%$ & 26 & 23 & $88,46 \%$ \\
\hline $\begin{array}{l}\text { Outorga onerosa do direito de } \\
\text { construir }\end{array}$ & 3 & $9,68 \%$ & 19 & 12 & $63,16 \%$ & 18 & 14 & $77,78 \%$ & 26 & 21 & $80,77 \%$ \\
\hline $\begin{array}{l}\text { Transferência do direito de } \\
\text { construir }\end{array}$ & 3 & $9,68 \%$ & 19 & 11 & $57,89 \%$ & 18 & 14 & $77,78 \%$ & 26 & 17 & $65,38 \%$ \\
\hline ZEIS/AEIS & 6 & $19,35 \%$ & 19 & 15 & $78,95 \%$ & 18 & 15 & $83,33 \%$ & 26 & 24 & $92,31 \%$ \\
\hline $\begin{array}{l}\text { Parcelamento, edificação ou } \\
\text { utilização compulsórios }\end{array}$ & 1 & $3,23 \%$ & 19 & 14 & $73,68 \%$ & 18 & 15 & $83,33 \%$ & 26 & 22 & $84,62 \%$ \\
\hline Operação consorciada & 3 & $9,68 \%$ & 19 & 13 & $68,42 \%$ & 18 & 16 & $88,89 \%$ & 26 & 20 & $76,92 \%$ \\
\hline Direito de preempção & 5 & $16,13 \%$ & 19 & 16 & $84,21 \%$ & 18 & 16 & $88,89 \%$ & 26 & 21 & $80,77 \%$ \\
\hline
\end{tabular}

Fonte: Pesquisa Observatório das Metrópoles/Núcleo Minas Gerais - Proex/PUC Minas - Fase (2002) e Pesquisa Observatório das Metrópoles/Núcleo Minas Gerais - Proex/PUC Minas - Plano Diretor (2006)

Nota 1: Em 2002, os municípios Confins, Sarzedo, Itatiaiuçu e Nova União não responderam os questionários aplicados. Não foram, portanto, considerados na composição da tabela.

Nota 2: Em 2006, os municípios de Baldim e Matozinhos não devolveram os questionários da pesquisa. Nova União foi desconsiderada na pesquisa, uma vez que os questionários retornados foram considerados inválidos. Em vista disso, os três municípios mencionados não entraram na composição da tabela.

Nota 3: Apesar de em 2002 ter sido aplicado apenas um questionário por município e em 2006 terem sido aplicados três questionários por município, os dados utilizados na composição dessa tabela se referem tão-somente às questões relativas à previsão legal dos instrumentos de política urbana.

e parcelamento, edificação ou utilização compulsórios, que em 2002 eram os menos adotados e em 2006 aparecem entre os mais mencionados. $\mathrm{O}$ instrumento direito de superfície, dentre os 31 municípios, aparecia em apenas 3,23\%. Em 2006, dos 31 municípios apenas 19 tiveram os questionários validados pelo coordenador técnico. Destes, 61,11\% afirmaram possuir o instrumento.

O mesmo aconteceu com o parcelamento, edificação ou utilização compulsórios. Já o IPTU progressivo no tempo teve ampliação ainda maior no que se refere à sua difusão dentro da RMBH. Em 2002, era nula sua adoção. Em 2006, dos 18 questionários validados para esse recorte espacial, esteve presente em 72,22\% dos municípios, segundo os coordenadores técnicos do plano diretor. Os dados de representantes da sociedade civil e também dos coordenadores políticos reforçam essa informação.

Outorga onerosa do direito de construir, transferência do direito de construir e operação consorciada representavam 3,23\% do 
total de municípios no ano de 2002. Em 2006, a operação consorciada constava em 51,61 municípios, enquanto a transferência do direito de construir em 45,16\%.

Apesar de em 2006 a maioria das informações prestadas pelos atores denotar maior utilização dos instrumentos, no geral não há convergência quanto às informações prestadas. Os mais evidentes se referem aos instrumentos: consórcio imobiliário, usucapião urbano, desapropriação e EIA, nos quais houve divergência significativa entre os atores do plano diretor.

A pesquisa tinha também o objetivo de analisar a natureza das políticas públicas municipais em matéria de habitação executadas na Região Metropolitana de Belo Horizonte-RMBH; e identificar as experiências alternativas de habitação popular existentes na $\mathrm{RMBH}$, a fim de avaliar a natureza deliberativa dessas políticas, bem como a efetividade do direito fundamental à moradia previsto no artigo $6^{\circ}$ da Constituição Republicana de 1988 . Em razão da grande recusa, por parte dos entrevistados, em responder os questionários utilizados para essa análise, o segundo objetivo não foi cumprido. Esse obstáculo ocasionou uma mudança de trajetória no objeto da pesquisa que, então, passou a avaliar a efetividade dos processos participativos de tomada de decisão a partir da compreensão que seus interlocutores têm dos instrumentos de política urbana.

\section{Conclusão}

(i) Apesar de os planos diretores serem considerados participativos, há divergência, entre os atores pesquisados, sobre a utilização dos instrumentos de política urbana previstos no Estatuto da Cidade. Isso demonstra que a compreensão desses instrumentos não parece ter sido apreendida, nem pelo poder públi$\mathrm{co}$, nem pela sociedade civil local. Várias razões podem justificar esse resultado, entre elas a ausência do que Pettit (2007) denomina de capacidade raciocinativa de participar e que Habermas (2004) denomina condições ideais de fala. Em outras palavras, os atores demonstram não ter entendimento das potencialidades de aplicação dos instrumentos de política urbana. Isso poderá comprometer a efetividade e a eficiência de seus resultados. Em síntese, a utilização dos instrumentos de política urbana, se existente, parece ter sido apenas nominal.

(ii) Nesse sentido, a legitimidade dos planos diretores elaborados por esses municípios parece ter sido apenas formal, uma vez que seus atores não foram capazes de sustentá-la de forma coerente. Por outro lado, se consideramos a democracia como processo, como sustenta Habermas (2004), um grande passo foi dado em direção à concretização do planejamento urbano participativo.

(iii) Por fim, no que se refere ao direito à moradia, pode-se dizer que evoluímos em direção à concretização do direito à cidade sustentável, ao menos sob o aspecto quantitativo, uma vez que boa parte de os planos diretores incorporaram instrumentos de política urbana diretamente vinculados ao direito de propriedade. 


\section{Referências}

ATENAS. Carta de Atenas. Disponível em: http://portal.iphan. gov.br/portal/baixaFcdAnexo.do;jsessionid=8B5B9ABE30EBCB OECE8737017EFB8B2B?id=233. Acesso em: 5 nov. 2008.

AZEVEDO, Sérgio de. Políticas públicas: discutindo modelos e alguns problemas de implementação. In: SANTOS JUNIOR, Orlando Alves dos et al. (Org.). Políticas públicas e gestão local: programa interdisciplinar de capacitação de conselheiros municipais. Rio de Janeiro: Fase, 2003.

BRASIL. Constituição (1988) Constituição da República Federativa do Brasil. 11. ed. atual. São Paulo: Revista dos Tribunais, 2006.

BRASIL. Código (2002) Código civil. 12. ed. atual. São Paulo: Saraiva, 2006.

BRASIL. Lei n. 10.257, de 10 de julho de 2001. Estatuto da Cidade. Regulamenta os arts. 182 e 183 da Constituição Federal, estabelece diretrizes gerais da política urbana e dá outras providências. Diário Oficial da União, Brasília, 11 jul. 2001.

BRASIL. Supremo Tribunal Federal. Ação direta de inconstitucionalidade. Art. $3^{\circ}$, caput e parágrafos, da Lei 9.262, de 12-11996, do Distrito Federal. Venda de áreas públicas passíveis de se tornarem urbanas. Terrenos localizados nos limites da área de proteção ambiental (APA) da Bacia do Rio São Bartolomeu. Processo de parcelamento reconhecido pela autoridade pública. Vendas individuais. Afastamento dos procedimentos exigidos na Lei 8.666, de 21-6-1993. Necessidade de comprovação. Inexigibilidade e dispensa de licitação. Inviabilidade de competição. Alegação de violação do disposto no art. 37, XXI, da Constituição do Brasil. Inocorrência. A dispensa de licitação em geral é definida no art. 24 da Lei 8.666/1993; especificadamente - nos casos de alienação, aforamento, concessão de direito real de uso, locação ou permissão de uso de bens imóveis construídos e destinados ou efetivamente utilizados no âmbito de programas habitacionais ou de regularização fundiária de interesse social, por órgãos ou entidades da administração pública - no seu art. 17, I, f. Há, no caso dos autos, inviabilidade de competição, do que decorre a inexigibilidade de licitação (art. 25 da lei). O loteamento há de ser regularizado mediante a venda do lote àquele que o estiver ocupando. Consubstancia hipótese de inexigibilidade, art. 25. Ação direta de inconstitucionalidade julgada improcedente. ADI 2.990, Rel. p/ o ac. Min. Eros Grau, julgamento em 18-4-2007, Plenário, Diário de Justiça da União, Brasília, 24 ago.2007.

GODINHO, Maria Helena de Lacerda; MENDONÇA, Jupira Gomes de (Org.). População, espaço e gestão na metrópole: novas configurações, velhas desigualdades. Belo Horizonte: Editora PUC Minas, 2003.

GODINHO, Maria Helena de Lacerda; NAVARRO, Renato Godinho. Movimentos sociais (populares), conselho municipal e órgão gestor na definição e implementação da política habitacional em Belo Horizonte - década de 1990. Cadernos Metrópole: desigualdade e governança. São Paulo: Educ; Pronex; CNPq, n. 7, 2002. 
nho. Orçamento participativo da habitação e democratização na gestão da política habitacional em Belo Horizonte. In: AZEVEDO, Sergio; FERNANDES, Rodrigo Barroso (Org.). Orçamento participativo: construindo a democracia. Rio de Janeiro: Renavan, 2005.

HABERMAS, Jürgen. A inclusão do outro: estudos de teoria política. Tradução George Sperber, Paulo Astor Soethe e Milton Camargo Mota. São Paulo: Loyola, 2004.

HESSE, Konrad. A força normativa da Constituição. Tradução Gilmar Ferreira Mendes. Porto Alegre: Sérgio Antônio Fabris, 1991.

KELSEN, Hans. Teoria geral do Direito e do Estado. Tradução Luis Carlos Borges. São Paulo: Martins Fontes, 1998.

PETTIT, Philip. Teoria da liberdade. Tradução Renato Sérgio Pubo Maciel. Coordenação e supervisão de Luiz Moreira. Belo Horizonte: Del Rey, 2007.

RIBEIRO, L. C. de Q. O estatuto da cidade e a questão urbana brasileira. In: RIBEIRO, L. C. Q.; CARDOSO, A. L. (Org.). Reforma urbana e gestão democrática: promessas e desafios do Estatuto da Cidade. Rio de Janeiro: Revan; Fase, 2003.

SOUZA, Celina. Federalismo e intermediação de interesses regionais nas políticas públicas brasileiras. Trabalho apresentado no Seminário Internacional sobre Reestruturação e Reforma do Estado: Brasil e América Latina no processo de globalização. São Paulo, 18 a 21 de maio de 1998.

\section{Endereço para correspondência}

Naiane Loureiro dos Santos

naiane@pucminas.br

Circlaine da Cruz Santos Faria

circlaine@pucminas.br

Marinella Machado Araújo

marinella@pucminas.br 
